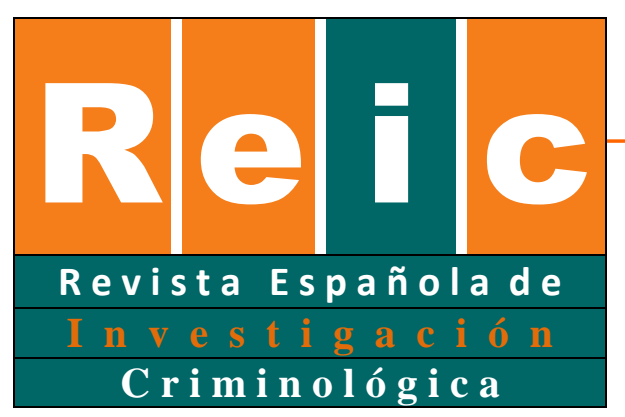

\title{
SERIE ESPECIAL: TRANSICIÓN DESDE LA DELINCUENCIA JUVENIL A LA DELINCUENCIA ADULTA ${ }^{1}$
}

\section{Patrones de la carrera delictiva: prevalencia, frecuencia, continuidad y desistimiento del delito}

\author{
Alex R. Piquero, J. David Hawkins, Lila Kazemian, David Petechuk \& \\ Santiago Redondo
}

El estudio empírico de la actividad delictiva y de su evolución a lo largo del tiempo ha sido un tema nuclear en la Criminología científica. Empezando por el trabajo pionero y descriptivo de Quetelet (1842), continuando por el clásico The Jack Roller, de Shaw (1931), y culminando en el estudio emblemático de Wolfgang, Figlio y Sellin (1972), Delinquency in a Birth Cohort, los análisis descriptivos y más básicos sobre la conducta criminal han proporcionado información relevante acerca de la proporción de individuos que delinquen, la cuantía de sus delitos, las respectivas participaciones según tipologías delictivas, y sobre el desistimiento de la actividad criminal (véanse revisiones a este respecto en Blumstein, Cohen, Roth, y Visher, 1986; Piquero, Farrington y Blumstein, 2003). Además, estas conclusiones sobre las carreras criminales han servido de base para la generación de distintas explicaciones criminológicas, y especialmente de diversas teorías del desarrollo vital (Farrington, 2005). Al mismo tiempo, tal información también ha facilitado algunos avances metodológicos y estadísticos importantes, de cara al estudio de los cambios que se producen en la actividad criminal, tanto intra-individuales como entre individuos, a lo largo del curso de la vida (Nagin, 2005).

\footnotetext{
${ }^{1}$ La monografía n. 1 de esta serie está publicada en el número 9 de la revista (2011). http://www.criminologia.net/pdf/reic/ano9-2011/a92011monografias2.pdf
} 
Particularmente relevante a este respecto ha sido el conocimiento adquirido acerca de los factores de riesgo para el delito, o elementos personales y sociales que se vinculan típicamente al inicio y a las variaciones que se producen en las carreras delictivas individuales (Ellis, Beaver y Wright, 2009; Redondo y Martínez-Catena, 2012). El método principal para obtener esta información ha correspondido a los denominados estudios longitudinales, o de seguimiento de los individuos a lo largo del tiempo, observando y midiendo la posible aparición o incremento de conductas problemáticas y antisociales, a la vez que se constatan las circunstancias de riesgo que se vinculan a ello (Bergman y Andershed, 2009; Farrington, Ttofi, y Coid, 2009; Remschmidt y Walter, 2009; Sarnecki, 2009).

Un modo parsimonioso y comprensivo de categorizar los diversos factores de riesgo delictivo que se han identificado en la investigación, es agruparlos en tres fuentes de influencia distintas (Redondo, 2008): 1) riesgos personales, inherentes a un individuo, 2) riesgos o carencias en el apoyo prosocial que se ha recibido (o, con mayor propiedad, del que se ha carecido), y 3) oportunidades delictivas a que el individuo se ve expuesto. Esta clasificación se ilustra en la figura 1, a partir de una intersección entre conjuntos de factores de riesgo de las tres naturalezas mencionadas. Desde esta perspectiva, un sujeto podría ser influido solamente por riesgos de una categoría, de dos categorías, o de las tres, lo que condicionaría la cualidad y magnitud de las influencias criminogénicas que le afectan, y, en consecuencia, su probabilidad de delito. 
Figura 1. Categorización de los factores de riesgo para el delito en tres fuentes o clases de riesgos principales

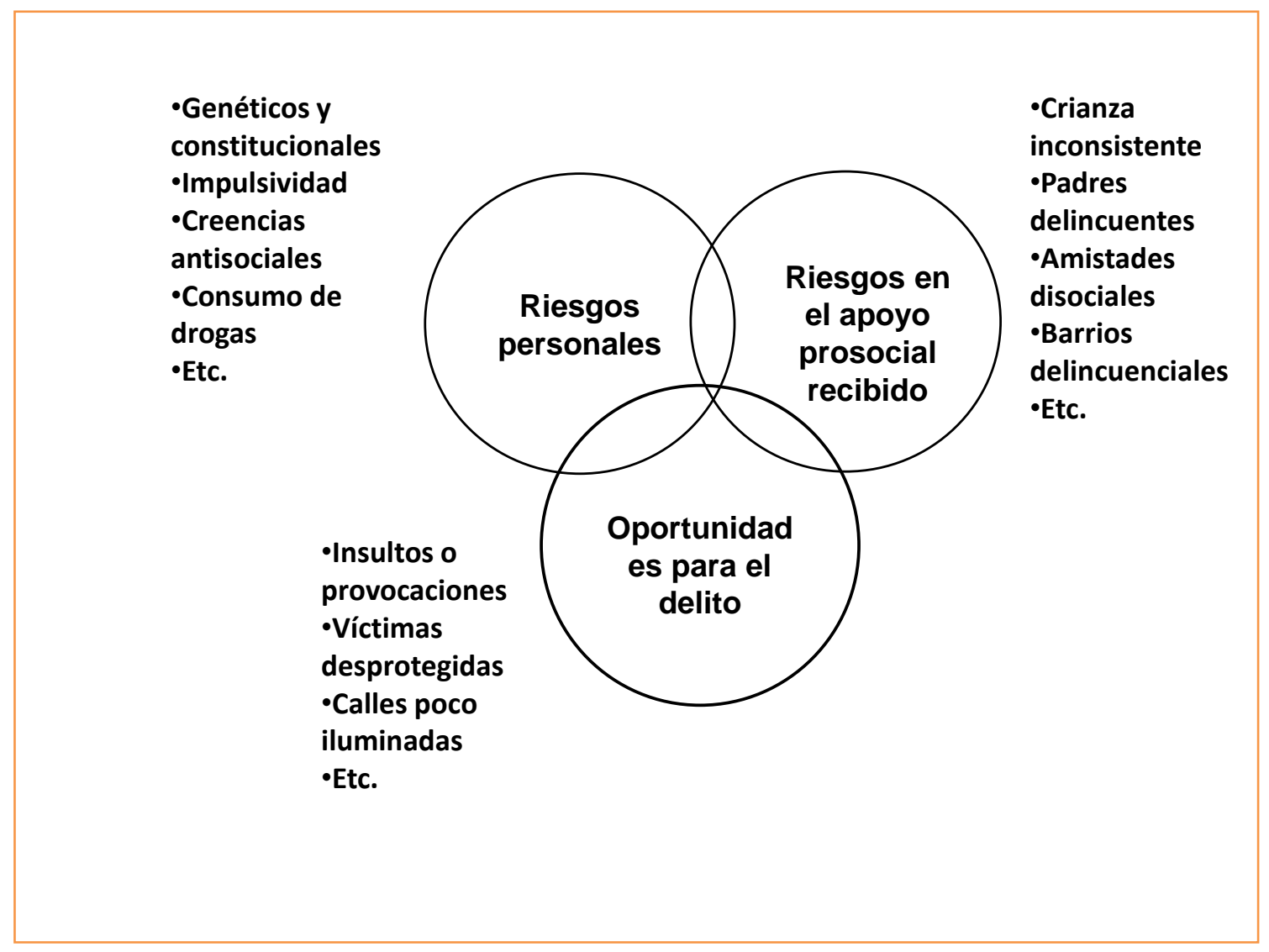

Fuente: Redondo, Martínez-Catena y Andrés (2011)

Entre los predictores personales de riesgo para la conducta delictiva pueden encontrarse, de acuerdo con la investigación, aspectos como los siguientes (Farrington y Loeber, 2013; Farrington, Loeber y Ttofi, 2012; Piquero y Brame, 2008; StouthamerLoeber, Loeber, Stallings, et al., 2008): 1) correlatos relativos a la genética y la constitución individual; 2) factores de personalidad; 3) predictores conductuales; 4) factores cognitivo-emocionales; y 6) dificultades en inteligencia y habilidades de aprendizaje.

Los riesgos en el apoyo prosocial harían referencia a las carencias sociales, económicas, educativas, etc., experimentadas por los individuos a lo largo de su vida, siendo a nuestros efectos particularmente relevantes las siguientes (DeLisi y Beaver, 2011; Farrington et al., 2012; Weerman, 2010): 1) las relativas al barrio en el que un niño vive; 2) las correspondientes a los problemas en la familia; 3) las dificultades 
relacionadas con la escuela; y 4) el riesgo que dimana de estar vinculado a amigos delincuentes. Por último, según ha puesto de relieve la criminología ambiental, también contribuirían a facilitar y promover los delitos, aquellas oportunidades criminales a que un individuo pueda verse expuesto, tales como la presencia de propiedades descuidadas o víctimas vulnerables.

Aunque los conocimientos precedentes sobre carreras delictivas y factores de riesgo han supuesto un avance notable en la criminología moderna, muchos de tales conocimientos han surgido a partir de diversos estudios sistemáticos y bien controlados, pero limitados en cuanto a las muestras evaluadas, las fuentes de datos utilizadas, y los periodos de observación. Por otro lado, muy pocos estudios se han ocupado de dimensiones específicas de la carrera criminal que conecten entre sí, en términos teóricos o aplicados, la delincuencia juvenil y la criminalidad adulta, periodo vital en que muchas carreras delictivas finalizan, mientras que solo un pequeño grupo de sujetos continúa delinquiendo.

Este trabajo dirige su atención precisamente a intentar responder a algunas de las carencias científicas mencionadas. Para ello, se analizarán las principales dimensiones de las carreras criminales, pero conectando los patrones delictivos de la adolescencia y la juventud con los de la edad adulta, incluyendo el análisis de los siguientes aspectos: prevalencia delictiva, frecuencia infractora, continuidad, inicio adulto en el delito, especialización delictiva, aceleración y desaceleración de la actividad criminal, estabilidad y cambio, y codelincuencia. Se concluirá con una síntesis general de la información revisada en este trabajo, y con una identificación de las prioridades para la investigación futura en este campo, con diversas recomendaciones dirigidas a profesionales y gestores de la justicia.

\section{Prevalencia}

La prevalencia delictiva, que es una de las dimensiones fundamentales de las carreras criminales, hace referencia a la proporción de individuos que participan en el delito en cada periodo de edad. El estudio pionero en este campo fue, en Estados Unidos, el Philadelphia Birth Cohort Study, que puso de relieve que alrededor de un tercio de los varones de la ciudad de Filadelfia (Estados Unidos) nacidos en 1945, habían ya tenido 
algún contacto con la policía, por razón de la comisión de algún delito, al llegar a la edad de 18 años (Wolfgang et al., 1972). Este mismo resultado se ha replicado en la mayoría de estudios longitudinales que se basan en cifras delictivas oficiales. El grueso de los estudios tienden a indicar que la prevalencia delictiva llega a su máximo en el periodo de la adolescencia media-tardía (en torno a los 15-19 años), y declina al principio de la década de edad de los 20 años (Blumstein et al., 1986; Piquero et al., 2003). Estas cifras delictivas propenden a ascender a edades más tempranas si los sujetos son evaluados mediante autoinforme, y a edades más tardías cuando se emplean datos delictivos oficiales, tales como los contactos de los jóvenes con la policía, las detenciones, y las condenas (Moffitt, Caspi, Rutter y Silva, 2001). Además, estas mismas tasas $\mathrm{y}$ tendencias suelen constatarse en diferentes muestras, periodos temporales, y contextos culturales.

Piquero et al. (2007) analizaron la prevalencia delictiva, a partir de sentencias condenatorias, en más de 400 varones de los barrios del sur de Londres, correspondientes al Estudio Cambridge sobre Desarrollo Delictivo. Este análisis mostró los siguientes resultados principales: 1) el periodo entre la adolescencia temprana y media evidencia una subida rápida de la prevalencia delictiva, desde el $2 \%$ a por encima del $10 \%$, alcanzando su pico más alto a los 17 años (10,7\%), lo que es seguido de un breve periodo de estabilidad, y de un declive paulatino de la proporción de sujetos que cometen delitos, que se extiende hasta la edad de 40 años; 2) en paralelo, la curva de prevalencia de condenas se acumula hasta la edad de 40 años, produciéndose su ascenso más repentino en torno a los 18 años, y deviniendo después dicha curva asintótica (o de ascenso desacelerado); 3) existen algunas diferencias en prevalencia delictiva según tipos de delitos, aunque en la mayoría de las categorías delictivas la prevalencia decrece con el paso del tiempo; y 4) la prevalencia delictiva acumulada (es decir, el número total de sujetos que han cometido un delito en algún momento de su vida), evaluada en varones mediante autoinforme, se aproxima al 100\% a la edad de 40 años (Farrington, Jollife, Loeber, et al., 2001). Es decir, al llegar a la edad de 40 años, la mayoría de los sujetos de esta muestra afirmaban haber cometido algún delito a lo largo de su vida.

Los estudios de autoinforme realizados en España han mostrado también elevadas prevalencias delictivas, tanto durante el año inmediatamente anterior a la realización del correspondiente estudio como, más aun, a lo largo de la vida de los 
sujetos. Por ejemplo, en un análisis en ciudades españolas de más de 50.000 habitantes, Rechea, Barberet, Montañés y Arroyo (1995), evaluaron mediante el Questionnaire for the International Study on Self-Report Delinquency, a 2.100 jóvenes, varones y mujeres, entre 14 y 21 años. El 81\% de ellos admitieron la comisión de alguna infracción o delito a lo largo su vida (incluyendo eso sí el consumo de drogas, a pesar de que no sea estrictamente un delito). Es verdad que esta amplia prevalencia infractora a lo largo de la vida se reducía bastante cuando se analizaban hechos más severos y claramente delictivos, bajando entonces el porcentaje al $20 \%$ de los jóvenes, y disminuía mucho más si se atendía exclusivamente a infracciones graves realizadas en el último año (no a lo largo de toda la vida), reduciéndose la prevalencia entonces al 3\%.

Por su parte, Garrido Martín, Heras y Gómez (2000) aplicaron el mismo cuestionario precedente a una muestra de 1.051 jóvenes salmantinos, tanto chicos como chicas. Los datos aquí tendieron a coincidir en lo esencial con los de Rechea et al. (1995), en el sentido de que mientras que fueron relativamente frecuentes aquellos comportamientos infractores de menor gravedad, como beber alcohol (lo que habían realizado "alguna vez" el $84,6 \%$ de los jóvenes, fumar marihuana $(37,9 \%)$ o conducir sin permiso $(33,5 \%)$, las conductas más graves, como golpear a alguien no familiar $(6 \%)$, prender fuego $(4,3 \%)$, robar una cartera o bolso $(2 \%)$, o sustraer una bicicleta o moto $(1,7 \%)$, fueron, como puede verse, bastante menos frecuentes.

Un nuevo estudio de autoinforme del Centro de Investigación en Criminología (Fernández Molina et al., 2009; Rechea, 2008), desarrollado en 2006 con una muestra de 3.077 jóvenes de 14 a 18 años, seleccionados del conjunto del territorio nacional produjo los siguientes resultados principales: la edad promedio a la que los jóvenes españoles decían haber cometido su primera infracción legal fue la edad de 13 años, aumentando después la frecuencia infractora, con el paso del tiempo, hasta los 17 años; las infracciones auto-informadas más frecuentes eran: bajar música ilegalmente mediante Internet (66\% de la muestra), consumir bebidas alcohólicas siendo menores de edad (63\%), haberse emborrachado (41\%), consumir cannabis (28\%), y participar en peleas $(22 \%)$. Mientras que otras conductas violentas y contra la propiedad de mayor entidad que las anteriores no superaban el $5 \%$.

En otras investigaciones europeas se han obtenido datos parecidos a los resultados españoles y norteamericanos anteriormente referidos. Por ejemplo, 
Gudjonsson, Eirnarsson, Bragason y Sigurdsson (2006) evaluaron a una muestra de 1.603 estudiantes daneses de educación superior, varones y mujeres, con una edad promedio próxima a 20 años, quienes en un $98 \%$ manifestaron haber participado en algún delito o infracción, generalmente de gravedad leve o moderada (consumo de alcohol u otras drogas, fugas del hogar, peleas...).

\subsection{Delitos violentos y contra la propiedad}

Loeber, Farrington, Stouthamer-Loeber y White (2008) evaluaron la prevalencia de infracciones y delitos contra la propiedad y comportamientos violentos, entre las edades 7-25 años, a partir de datos de dos cohortes de edad definidas sobre el conjunto de sujetos del Pittsburgh Youth Study (dividiendo para ello la muestra en dos subgrupos de análisis: los más jóvenes, menores de 19 años, y los más mayores, que al realizarse este análisis contaban con 20 años o más). Por lo demás, las evaluaciones que siguen, para cada una de estas dos submuestras, toman en consideración, a efectos de los análisis aquí realizados, las diferentes edades de los sujetos sobre las que consta información. De la cohorte de los sujetos más jóvenes, en torno al $25 \%$ habían sido ya detenidos por violencia grave a la edad de 19 años (y alrededor del 10\% sentenciados por ello), mientras que casi un 20\% habían sido detenidos por robos graves (y un 20\% sentenciados por esto mismo). Por lo que se refiere al grupo de mayor edad, un $33 \%$ de los sujetos habían sido detenidos por delitos violentos graves ya a la edad de 25 años (y 1 de cada 6 condenados por tales delitos), y un paralelo porcentaje del $33 \%$ detenidos por hurtos/robos graves (y un $20 \%$ condenados por tales delitos).

En la cohorte más joven del estudio Pisttsburg, la prevalencia autoinformada de violencia moderada-grave alcanzó su máximo (alrededor del 5-6\%) en la adolescencia temprana (edades entre 13 a 16 años), declinando pronto a niveles entre moderados y bajos. En la cohorte de mayor edad, los delitos violentos graves alcanzaron su cota máxima (alrededor del 11\%) a las edades 18-19, bajando después de modo brusco, mientras que la violencia moderada fue más elevada a las edades 14-15 (17\%), declinando luego. En conjunto, la muestra más mayor en edad, probablemente debido al periodo histórico unos años anterior en el cual llegaron a su adolescencia (periodo en 
que probablemente existía mayor violencia delictiva en general), mostró más delitos violentos graves, en comparación con el grupo de los sujetos más jóvenes.

En relación con los hurtos/robos, los resultados referidos a los sujetos más jóvenes indicaron que la prevalencia de los hurtos/robos de gravedad moderada alcanzaba su mayor cota (19\%) a las edades 14-15 años, bajando posteriormente; mientras que para el caso de los hurtos/robos graves (que implican, por ejemplo, forzar y robar en el interior de un vehículo o sustraer el vehículo en sí), la prevalencia era baja durante la infancia media (1\%, a las edades 7-10 años), alcanzaba su mayor nivel (4\%6\%) a las edades de 14-17 años, y después decaía. Para el sector muestral de jóvenes de mayor edad (considerando aquí el amplio intervalo 13-25), los hurtos leves decrecieron desde el 42\% (a la edad de 13 años) al 1\% (a la edad de 25 años). Para el caso de los hurtos/robos de gravedad moderada se constató una prevalencia máxima (del 32\%) a la edad de 15 años (32\%), y una mínima (del 4\%) a la edad de 25 años; y en lo concerniente a los hurtos/robos graves, la prevalencia osciló entre $8 \%$ y $11 \%$ a las edades 13 a 15 años, y decreció prácticamente a cero a la edad de 25 años.

Al igual que sucedía en relación con los delitos violentos, la cohorte de sujetos de más edad evidenció en conjunto mayores tasas de hurtos/robos que el grupo de menor edad. En ambos grupos (los de edades más jóvenes y los más mayores), la prevalencia de hurtos/robos auto-informados fue mucho mayor que la correspondiente a conductas violentas, y también fue menor la prevalencia de robos graves que la de hurtos más leves. A la edad de 19 años, alrededor del 74\% de los sujetos más jóvenes ya se habían visto implicados en hurtos menores, en contraste con un 50\% que habían participado en hurtos/robos de gravedad moderada, y menos del 20\% que se habían visto envueltos en hurtos/robos graves. Los hechos violentos fueron, obviamente, más infrecuentes: de los sujetos más jóvenes, un 33\% se habían inmiscuido en violencia moderada y un $20 \%$ en violencia grave.

¿Pueden sostenerse los anteriores resultados y conclusiones cuando se emplean como criterio, no datos de autoinforme, sino cifras delictivas oficiales sobre detenciones? Entre la cohorte muestral más joven del estudio Pittsburgh, la prevalencia de detenciones por actos de violencia grave alcanzó su punto máximo (7\%) a los 16 años y disminuyó posteriormente, mientras que el pico o cota de violencia moderada se observó a las edades de 14 y 18 años (en ambos casos, un 4\%). Entre la cohorte de 
sujetos de mayor edad (analizada a estos efectos desde la edad de 13 años en adelante), la prevalencia de violencia moderada alcanzó su punto máximo (7\%) a las edades de 18 y 21, y de violencia grave a los 19 años (10\%). En cuanto a los delitos contra la propiedad, la prevalencia de detenciones por hurto/robo de gravedad moderada alcanzó su mayor cota a las edades de 16 años (10\%) y 18 años (9\%), mientras que el pico de mayor prevalencia por robo grave se produjo a los 16 años (5\%) para el caso de la cohorte de los sujetos más jóvenes. Para el grupo de mayor edad, las detenciones por hurtos y robos de gravedad moderada y severa alcanzaron su punto máximo a los 16 años (15\% para los hurtos/robos de gravedad moderada, 12\% para los hurtos/robos graves). ${ }^{2}$

En un análisis último del trabajo sobre el estudio Pittsburgh al que aquí se está aludiendo, Loeber et al. (2008) definieron y evaluaron medidas delictivas combinadas, tanto para la delincuencia violenta como para el robo, a partir de integrar, para cada modalidad delictiva, datos de autoinforme y de delincuencia oficial. En relación con los delitos violentos, el grupo de mayor edad mostró mayores niveles de violencia a todas las edades, aunque los más jóvenes presentaron un pico de conducta violenta ligeramente más temprano (a las edades 13-16 años) en comparación con los más mayores (cuya cota de violencia se situó a las edades 18-19 años). En lo relativo al robo, también hubo una superior prevalencia infractora de la cohorte más mayor para todas las edades, con un pico o cota máxima alrededor de las edades entre 14 y 16 años para ambos grupos, pero con un descenso mucho más rápido de la prevalencia anual entre la cohorte de sujetos más jóvenes.

\footnotetext{
${ }^{2}$ Una de las características clave del Pittsburgh Youth Study es la combinación que efectúa de los dos tipos de medidas de delincuencia señaladas, tanto las de autoinforme como las oficiales. Los datos longitudinales que contienen paralelamente medidas de autoinforme y oficiales son en Criminología más bien la excepción que la norma. En general, los resultados de autoinforme indican que una amplia proporción de los sujetos participan durante la adolescencia temprana en delitos graves, a pesar de que muchos no serían detenidos hasta la adolescencia tardía, y menos aún oficialmente condenados, debido al proceso de filtrado del sistema de justicia. En general, los análisis efectuados por Loeber y col. (2008:124-125) llegan a la conclusión de que se estarían produciendo graves errores de identificación delictiva de los sujetos, en la medida en que menos del $70 \%$ de los delincuentes violentos graves en las dos cohortes juveniles aquí analizadas serían formalmente detectados.
} 


\subsection{Varones y mujeres}

Moffitt et al. (2001) efectuaron un amplio análisis de la conducta antisocial en función del sexo de los individuos, a partir de la cohorte de 1.000 sujetos, varones y mujeres, hasta la edad de 21 años, evaluados en Nueva Zelanda, en el marco del Estudio Multidisciplinar Dunedin sobre Desarrollo Humano y Salud. Para ello, se analizaron datos de autoinforme de los propios sujetos, informes de los padres acerca de las posibles conductas infractoras de sus hijos, y archivos oficiales sobre detenciones y condenas. Con independencia de las fuentes de datos consideradas, en la evaluación realizada hasta la edad de 21 años, los varones habían cometido en todos los casos más infracciones que las mujeres. Aun así, ambos sexos mostraron una prevalencia de comportamiento antisocial más parecida entre ellos durante el periodo de la adolescencia media, y particularmente en lo referido a las infracciones de consumo de drogas y alcohol.

Espada Sánchez, Méndez e Hidalgo (2000) analizaron específicamente la problemática del consumo de alcohol en España entre los jóvenes de 11 a 17 años, a partir de una encuesta aplicada a una muestra de 1.013 jóvenes. Los resultados indicaron que el 67,7\% de los jóvenes evaluados habían consumido alguna vez alcohol, siendo el 37,8\% consumidor habitual. La edad media de inicio del consumo era bastante temprana, de 12.2 años. A medida que aumentaba la edad, la tasa de bebedores habituales era significativamente más alta: mientras que a los 12 años ésta era del 15,6\%, a la edad de 17 años ascendía hasta un 78,7\%. Una amplia mayoría de adolescentes manifestaron beber alcohol especialmente los fines de semana (87,7\%), aunque un 7\% lo hacía durante toda la semana, y un 5,3\% solamente entre semana. Así mismo, se analizaron los motivos que los jóvenes aducían para el consumo de alcohol, apareciendo como más destacados la curiosidad y la presión social. De los jóvenes que se confesaban consumidores de alcohol en el periodo en que se realizó el estudio, un $10 \%$ admitieron haber llegado hasta la intoxicación etílica en alguna ocasión. También se analizó en este estudio si los jóvenes podían estar imitando modelos familiares a este respecto. Se constató que aquellos adolescentes que bebían habitualmente, con mayor probabilidad tenían progenitores que también bebían a diario. 
En el mismo sentido, Rodríguez, Martínez, Paíno, Hernández e Hinojal (2002) analizaron, para una muestra de encarcelados en España, la relación existente entre los antecedentes de adicción, psicopatológicos y penales de los padres, y el consumo y la conducta delictiva de los sujetos que cumplían condena en prisión. Para ello se realizó una entrevista en profundidad a 87 presos. Los principales resultados de este estudio fueron los siguientes: 1) se constató una correlación significativa entre los antecedentes penales del padre y el tipo de conducta delictiva del sujeto; 2) el resto de variables predictoras analizadas, y, en concreto, los antecedentes psicopatológicos y de consumo de tóxicos de los padres, no mostraron relación significativa con la conducta delictiva y de consumo de drogas por parte de los sujetos de la muestra. A pesar de ello, sí que se constató cierta tendencia a que cuando los padres habían sido o eran consumidores de drogas, más probablemente los hijos también lo fueran.

Tornando al tema central de este epígrafe, acerca de la conducta delictiva en función del sexo, en el estudio Dunedin los hombres mostraron una tendencia general a involucrarse en delitos más graves que las mujeres, y a estar más representados en los registros criminales oficiales (Moffitt et al., 2001). Las mujeres criminalmente más activas, delinquieron en una tasa promedio mucho más baja que los hombres criminalmente más enérgicos. Por último, la prevalencia delictiva de varones y mujeres aumentó entre finales de la infancia y el periodo adolescente, alcanzando su máximo entre la adolescencia media y tardía, y disminuyendo después.

En España, la mayor prevalencia delictiva de los varones puede verse claramente reflejada en las cifras oficiales sobre menores condenados, por delitos o faltas. La tabla 1 recoge tanto el número como el porcentaje de mujeres y hombres condenados en 2011, en el rango de edades de responsabilidad penal de los menores, que cubre el intervalo entre 14 y 17 años. 
Tabla 1. Menores condenados según edades y sexo (año 2011)

\begin{tabular}{|l|l|l|l|l|}
\hline Edad & \multicolumn{2}{|l|}{ Mujeres } & \multicolumn{2}{l|}{ Hombres } \\
\hline $\mathbf{1 4}$ & 321 & $20 \%$ & 1.284 & $80 \%$ \\
\hline $\mathbf{1 5}$ & 413 & $17,5 \%$ & 1.945 & $82,5 \%$ \\
\hline $\mathbf{1 6}$ & 527 & $16,4 \%$ & 2.680 & $83,6 \%$ \\
\hline $\mathbf{1 7}$ & 547 & $14 \%$ & 3.333 & $86 \%$ \\
\hline Total & 1.808 & $16,4 \%$ & 9.242 & $83,6 \%$ \\
\hline
\end{tabular}

Fuente: Redondo y Garrido, 2013, a partir del Instituto Nacional de Estadística

En la tabla precedente, lo primero que destaca es la superior participación de los varones en el delito, a todas las edades, siendo autores en promedio del 83,6\% de los delitos condenados, frente a un 16,4\% de mujeres; además, la participación relativa de las chicas en la delincuencia (en contraste con los varones) se va reduciendo con la edad, bajando dicha participación, del 20\% existente a la edad de 14 años al 14\% a la edad de 17.

Resumen. Aunque en estudios de autoinforme la mayoría de los individuos refieren haber efectuado algún tipo de conducta infractora con antelación a la edad adulta temprana, los registros oficiales relativos a contactos con la policía, detenciones y condenas muestran una prevalencia delictiva más baja (aproximadamente del $20 \%$ al $40 \%$, dependiendo de las fuentes de datos, períodos de seguimiento, etc.). Ello significa que la mayoría de las infracciones (muchas de ellas, generalmente leves) no son detectadas y formalmente perseguidas. Los análisis indican una cota máxima de delitos auto-informados durante el periodo de la adolescencia temprana y un máximo de prevalencia delictiva oficial (de acuerdo con cifras policiales, etc.) durante la adolescencia tardía. Estas tasas varían parcialmente según el tipo de delito, con un aumento anterior de la prevalencia de los delitos más leves (generalmente contra la propiedad) y un incremento más tardío de los más graves (incluyendo los delitos violentos). En los estudios que incluyen información sobre prevalencia delictiva en función del sexo de los sujetos, la evidencia tiende a mostrar que los hombres presentan un pico o cota de prevalencia mayor y anterior, a la cota evidenciada por las mujeres. 


\section{Frecuencia}

La segunda dimensión clave de la carrera criminal, la frecuencia, mide el número de delitos cometidos por cada sujeto. La evidencia acerca de la frecuencia infractora individual (que suele ponderarse como el número de delitos cometidos por delincuente en el periodo de un año) suele ser más compleja y difícil de evaluar e interpretar que la estimación de la prevalencia delictiva, o participación grupal en el delito.

A partir de evaluar los registros oficiales de condenas, Piquero et al. (2007) examinaron el número de delitos totales cometidos por los varones integrantes del Estudio Cambridge, en el que se había evaluado a más de 400 sujetos, durante un periodo de seguimiento superior a 40 años. A la edad de 40 años, estos sujetos habían acumulado un total de 760 condenas, con picos o cotas máximas a las edades de 17 años (69 condenas) y 18 años (67 condenas), a lo que siguió un descenso paulatino de esta tasa a lo largo de la edad adulta. Por otro lado, cuando los autores examinaron la frecuencia de la delincuencia individual a través de grupos de edad (en los intervalos 10-15 años, 16-20, 21-25, 26-30, 31-35, y 36-40), se observó en general un aumento temprano de la frecuencia delictiva, seguido de una disminución constante a lo largo de los periodos siguientes. Una ascensión semejante se constató por lo que se refiere a los delitos violentos, aunque en este caso las frecuencias delictivas fueron mucho más bajas, al ser los delitos violentos mucho más raros o atípicos.

Loeber y col. (2008) también proporcionan un análisis detallado de la frecuencia de delitos violentos y de robo en diferentes intervalos de edad, a partir del Estudio Pittsburgh, en relación a las dos cohortes de edades a que se ha hecho mención (una de sujetos más jóvenes y otra más mayores). En la cohorte muestral más joven, sus análisis indicaron que la frecuencia anual de delitos violentos de gravedad moderada y severa se incrementó a lo largo de tres intervalos de edad sucesivos (10-12, 13-16, 17-19), alcanzando un pico máximo, de alrededor de dos delitos anuales por delincuente, en las edades 17-19 años, tanto en relación con la violencia moderada como grave. En la cohorte de mayor edad, la frecuencia de infracciones violentas auto-informadas alcanzó su máximo, de en torno a cuatro infracciones por infractor y año, durante la adolescencia tardía (edades 17-19), para luego decaer durante la edad adulta temprana (edades 20-25). 
En cuanto a la frecuencia de los robos, los resultados de la cohorte de sujetos más jóvenes indicaron que la frecuencia anual de robos auto-informados aumentó hasta la adolescencia temprana (edades 13-16), y después se mantuvo estable o disminuyó a lo largo de la adolescencia tardía. Entre la cohorte de más edad, para diversas categorías de hurto/robo, la frecuencia delictiva fue mayor en la adolescencia tardía (de 17 a 19 años, con entre 3.05 y 5.04 infracciones por delincuente), y el robo grave fue mucho menos frecuente en la edad adulta temprana (edades 20 a 25), a razón de unos 2 robos por delincuente.

En resumen, las frecuencias anuales de hurtos/robos auto-informados fueron más altas entre los chicos más mayores del estudio Pittsburgh, que entre los más jóvenes; y la frecuencia por hurtos/robos tendió a ser más elevada, en la mayoría de las comparaciones, que la frecuencia de acciones violentas. Para la cohorte de mayor edad, en sus primeros años de carrera delictiva fueron más habituales los hurtos y robos, mientras que en la parte posterior de sus carreras delictivas resultaron más comunes los delitos violentos (Loeber et al., 2008).

Volviendo a las tasas de detención, en el grupo más joven (en que se analizaron los intervalos de edad de 10-12, 13-16, y 17-19 años), la frecuencia anual de detenciones por violencia moderada se mantuvo estable desde finales de la niñez a la adolescencia tardía (a razón de 0.4-0.5 delitos/detenciones por año); mientras que la frecuencia anual de detenciones por violencia grave fue similar a la de violencia moderada, y se mantuvo estable desde finales de la niñez a la adolescencia tardía (a razón de 0.5-0.6 delitos/detenciones por año). Entre la cohorte de más edad (a partir de analizar los intervalos de edad 13-16, 17-19, y 20-25), la frecuencia anual de detenciones, tanto para violencia moderada como grave, fue mayor durante la adolescencia tardía que en la temprana, mientras ambas formas de violencia (moderada y grave) disminuyeron durante la primera edad adulta (intervalo de 20 a 25 años).

Con respecto a la frecuencia de detención por robo, en la cohorte muestral más joven, la frecuencia de hurto/robo de gravedad moderada aumentó desde finales de la infancia a la adolescencia tardía (llegando a 0.87 detenciones por año), pero no amentó tanto para los hurtos/robos graves (en que fue de 0.57 detenciones por año) (Loeber et al., 2008). Para la cohorte de más edad, la frecuencia de las detenciones por hurto/robo fue mayor, para el caso de los hurtos/robos de gravedad moderada, durante la 
adolescencia temprana y tardía (cifrándose en 0.9 a 1.0 detenciones por delincuente); mientras que las detenciones por robo grave también alcanzaron su punto máximo durante la adolescencia temprana y tardía (en torno a 0.8-0.9 detenciones por delincuente), con una subsiguiente disminución desde la adolescencia a la edad adulta temprana.

Resumen. A diferencia de las tendencias observadas en relación con la prevalencia, que suelen mostrar sus cotas delictivas máximas a principios de la adolescencia tardía y una disminución gradual después de la edad de 18 años, la frecuencia delictiva de los individuos parece variar en edades en función de aspectos como la composición de las muestras, las medidas de delincuencia utilizadas, y los períodos de observación o seguimiento. Aun así, la frecuencia anual de delincuencia individual parece alcanzar su punto máximo a finales de la adolescencia y, en general, disminuir a continuación. Sin embargo, para un grupo muy reducido de delincuentes, se mantendría estable durante un tiempo relativamente largo. Además, las frecuencias individuales de delito acostumbran a ser más altas para los delitos contra la propiedad que para los delitos violentos, aunque en ambos casos van disminuyendo con el tiempo. Por último, las frecuencias delictivas suelen ser claramente más elevadas cuando se evalúan a partir de las infracciones auto-informadas que mediante cifras oficiales, debido a que, como es conocido, la mayoría de los delitos cometidos no suelen descubrirse y dar lugar a un registro delictivo oficial.

\section{Continuidad}

Se ha documentado una relativa tendencia a la continuidad de la conducta antisocial desde la infancia a la adolescencia, y después a la edad adulta. Como puso de relieve Robins (1978), "el comportamiento delictivo adulto casi siempre requiere que haya existido una previa conducta antisocial juvenil" (p. 611). Pero por otro lado, la mayoría de los niños y adolescentes que han realizado conductas antisociales en edades juveniles no van a convertirse en infractores adultos (LeBlanc y Loeber, 1998; Loeber y LeBlanc, 1990), y menos aún aquellos chicos que ni siquiera en la adolescencia cometieron delitos. 
Si se toma como criterio de persistencia delictiva el cometer delitos tanto antes como después de la adolescencia, según Blumstein et al. (1986), entre el 30 y el 60 por ciento de los menores delincuentes que tuvieron expedientes policiales o pasaron por los tribunales de menores, persistieron después como delincuentes adultos, con al menos una detención o condena, en la edad adulta, por un delito grave (véanse también McCord, 1978, y Wolfgang, Thornberry y Figlio, 1987). A partir de datos oficiales sobre más de 27.000 individuos nacidos en Philadelphia en 1958, de quienes se realizó un seguimiento desde el nacimiento hasta los 26 años, Tracy y Kempf-Leonard (1996) encontraron que había mayor continuidad delictiva que discontinuidad. Entre aquellos sujetos que durante su adolescencia tuvieron expedientes delictivos oficiales, el 32,5\% también fueron detenidos en la edad adulta, en contraste con solo un 7,6\% de detenciones experimentadas por quienes no contaban con procesamientos delictivos como menores. Dicho en términos positivos, aunque el 67,5\% de quienes habían cometido delitos juveniles no continuaron delinquiendo en la edad adulta, de quienes no habían cometido delitos juveniles, más del 92,4\% tampoco los cometieron en su vida adulta.

En Estados Unidos, en relación con las etnias de pertenencia de los sujetos, Tracy y Kempf-Leonard (1996) encontraron que los sujetos de raza negra tenían en general mayor probabilidad de ser detenidos en la edad adulta (17,4\%), seguidos de los hispanos $(13,1 \%)$, y de los de raza blanca $(9,1 \%)$. No obstante, en todos los grupos étnicos, al aumentar la frecuencia oficial de la delincuencia juvenil (desde no haber cometido ningún delito, a haber cometido un solo delito, a cierta reincidencia delictiva 2 a 4 delitos-, y a una delincuencia crónica -5 o más delitos), también aumentó paralelamente la probabilidad de delincuencia oficial adulta. Por ello, más allá del grupo racial o étnico de pertenencia, de entre los jóvenes que no han cometido delitos en su adolescencia surgen posteriormente muchos menos delincuentes adultos que de entre las filas de quienes fueron delincuentes juveniles crónicos, que nutren en todos los casos el mayor porcentaje de delincuentes adultos.

En síntesis, el conocimiento, a partir de registros oficiales, de las prevalencias delictivas juveniles, puede ayudar a predecir las futuras prevalencias delictivas adultas. En las investigaciones aquí revisadas, la condición de haber sido procesado o condenado como delincuente juvenil, se asoció significativamente, en los varones de 
todos los grupos raciales, a la de ser procesado o condenado como delincuente adulto; dicha asociación se observó también, aunque en menor medida, para el caso de las mujeres (probablemente, tal vinculación no pudiera detectarse con tanta claridad debido al menor tamaño de las muestras de mujeres). Frente a quienes contaban con antecedentes delictivos juveniles, aquellos que eran detenidos por primera vez en la edad adulta, solían serlo con mucha menor frecuencia (generalmente una sola vez), y no antes de los 26 años. Estos resultados sugieren un alto grado de continuidad de la probabilidad de ser detenido (o, contrariamente, de no ser detenido), entre la adolescencia y la edad adulta.

Loeber y col. (2008) también examinaron en el estudio Pittsburgh la persistencia de la conducta delictiva, a partir de auto-informes y registros oficiales de condenas, y hallaron lo siguiente: 1) prácticamente uno de cada cinco jóvenes delincuentes graves, devino delincuente persistente a lo largo de un período de 6 años o más; 2) se encontró un mayor nivel de persistencia delictiva grave $(71 \%)$ para aquellos sujetos con un inicio delictivo temprano (entre las edades 10-12 años, para la cohorte muestral de sujetos más jóvenes), en comparación con la menor persistencia (32\%) de aquellos individuos que habían comenzado a delinquir más tardíamente, durante el periodo de la adolescencia temprana (entre las edades 13-15 años); y 3) entre el $40 \%$ y el $50 \%$ de quienes fueron infractores prematuros, presentando tempranamente una gravedad delictiva entre moderada y severa, persistieron en el delito durante un período de alrededor de 7-9 años. En síntesis, se constató que un reducido grupo de delincuentes persistentes cometían una tasa elevada de delitos durante un periodo de tiempo prolongado.

Para evaluar la continuidad delictiva, Piquero et al. (2007) examinaron, a partir del Estudio Cambridge, las condenas experimentadas por los sujetos entre estos dos períodos de edad distintos y sucesivos, y en concreto el intervalo de edad 10-15 años y el periodo de edades 16-20 años. De los 67 varones que contaban con registros delictivos a las edades 10-15 años (excluidos dos sujetos que habían fallecido antes de los 20 años), 46 de ellos (el 67\%) tuvieron nuevos expedientes por delito entre los 16 y los 20 años; en cambio, de los 340 casos que no habían sido condenados entre las edades de 10 a 15 años, solo 58 de ellos (el 17\%) experimentaron alguna condena por delito entre los 16 y 20 años. Un análisis de estos datos mediante el índice odds ratio puso de relieve que el que un sujeto hubiera sido sancionado por delito en las edades 
entre 10 y 15 años aumentaba en más de 9 veces su probabilidad de ser condenado de nuevo entre las edades de 16 a 20 años.

En relación con la persistencia delictiva, en España, aunque no existen estudios longitudinales semejantes a los anteriores, puede disponerse de algunas investigaciones y análisis sobre la reincidencia de los menores que han cumplido medidas judiciales, que se recogen en la tabla 2.

Tabla 2. Estudios españoles de reincidencia juvenil y correlatos principales asociados a la reincidencia

\begin{tabular}{|c|c|c|c|}
\hline Estudios & $\begin{array}{l}\text { Muestra } \\
\text { (comunidad } \\
\text { autónoma): edad } \\
\text { promedio }\end{array}$ & $\begin{array}{ll}\text { Tasa de } & \\
\text { reincidencia } & \\
\text { (años de } & \\
\text { seguimiento) }\end{array}$ & $\begin{array}{l}\text { Correlatos principales } \\
\text { asociados a la reincidencia }\end{array}$ \\
\hline $\begin{array}{l}\text { Capdevila, } \\
\text { Ferrer y Luque } \\
(2006)\end{array}$ & $\begin{array}{l}2.903 \text { (Cataluña): } \\
16,5\end{array}$ & $22,7 \%$ & $\begin{array}{l}\text {-Varones } \\
\text {-Menor edad } \\
\text {-Más riesgos sociofamiliares }\end{array}$ \\
\hline $\begin{array}{l}\text { Bravo, Sierra y } \\
\text { del Valle (2007) }\end{array}$ & $\begin{array}{l}382 \text { (Asturias): } \\
\text { Varones: } 16,7 \\
\text { Chicas: } 17\end{array}$ & $\begin{array}{l}29,6 \% \quad(1-4 \\
\text { años })\end{array}$ & $\begin{array}{l}\text { (antecedentes, patologías) } \\
\text {-Maltrato físico } \\
\text {-No vivir con la familia/tener }\end{array}$ \\
\hline $\begin{array}{l}\text { San Juan, Ocáriz } \\
\text { y De la Cuesta } \\
(2007,2009)\end{array}$ & $\begin{array}{l}\text { Todos los jóvenes } \\
\text { en medio abierto } \\
\text { en el periodo } \\
\text { 2003-2004 (País } \\
\text { Vasco) }\end{array}$ & $21,5 \%$ (5 años) & $\begin{array}{l}\text { domicilio fijo } \\
\text {-Trastorno mental, } \\
\text { hiperactividad, impulsividad, } \\
\text { consumo de drogas } \\
\text {-Fracaso }\end{array}$ \\
\hline $\begin{array}{l}\text { García, Ortega y } \\
\text { De la Fuente } \\
\text { (2010): Meta- } \\
\text { análisis de } 17 \\
\text { estudios previos }\end{array}$ & $\begin{array}{l}16.502 \text { (España): } \\
14,68 \text { años }(86 \% \\
\text { varones) }\end{array}$ & $\begin{array}{l}26,12 \% \\
(\mathrm{Sd}=11,27)\end{array}$ & $\begin{array}{l}\text { escolar/formación/trabajo } \\
\text {-Amigos/pareja delincuentes } \\
\text {-Más antecedentes/delitos } \\
\text { violentos } \\
\text {-Experiencia de } \\
\text { internamientos }\end{array}$ \\
\hline
\end{tabular}

Fuente: Redondo y Garrido, 2013 
Como puede verse en la tabla, gran parte de las muestras evaluadas en estos estudios españoles estaban integradas por jóvenes infractores que habían cumplido diversos tipos de medidas judiciales, pero, sobre todo, medidas de cariz comunitario o abierto. Como tasa de reincidencia promedio puede tomarse la ofrecida por el metaanálisis de Ortega, García y De la Fuente (2010), que es del 26,12\%. En la columna derecha de la tabla se resumen, a partir de todos estos estudios, los correlatos más frecuentes que se asociaron a la reincidencia delictiva de los menores. Entre ellos se encuentran factores de riesgo individuales y estáticos, como el hecho de ser varón y ser más joven, una mayor impulsividad o trastorno hiperactivo, haber sufrido maltrato físico, contar con antecedentes delictivos o haber consumido drogas; y otros de cariz más social o experiencial, como puedan ser los riesgos sociofamiliares, vivir fuera de la familia o carecer de domicilio fijo, fracaso académico, y tener amigos o una pareja delincuentes.

La mayor reincidencia delictiva también se asoció, con carácter general, al hecho de haber cumplido previamente medidas de internamiento en centros de menores. Así se puso igualmente de relieve en un estudio de Capdevila, Ferrer y Luque (2008), por lo que se refiere a la reincidencia de aquellos menores que había cumplido medidas de internamiento en Cataluña en el período 2006-2007. Un total de 498 jóvenes conformaron esta muestra, estableciéndose para evaluar la reincidencia un período de seguimiento de 2 y 3 años. Los resultados obtenidos en este estudio cifran la tasa de reincidencia de estos menores que habían estado institucionalizados en un $62 \%$, la mayor parte de los cuales reincidieron antes de 6 meses desde su desinternamiento, generalmente en delitos contra la propiedad.

Resumen. La mayoría de los estudios anteriormente analizados muestran una fuerte continuidad o persistencia de la conducta delictiva, especialmente entre períodos de edades adyacentes o próximos. La fuerza de tal continuidad delictiva se incrementa linealmente en función del número de delitos cometidos previamente; es decir, aquellos sujetos que participaron con antelación en más delitos, tendían a mostrar una mayor y más prolongada continuidad delictiva que los que con anterioridad, o bien no habían cometido delitos o habían cometido menos. O sea, que existiría también un patrón de discontinuidad delictiva relacionado con el hecho de haber cometido previamente menos delitos. En general, estos mismos resultados se obtienen en muestras diferentes, 
con distintas características demográficas (varones/mujeres, diferentes etnias), para diversos períodos de tiempo, y con variadas duraciones de las observaciones o seguimientos.

No obstante, también hay que ser precavidos en relación con los análisis sobre continuidad delictiva, ya que determinados sesgos metodológicos o errores a la hora de medir la continuidad/discontinuidad, podrían llevar a conclusiones erróneas. Por ejemplo, el sesgo de medida que es inherente a las cifras oficiales, ya que no todos los delincuentes que cometen uno o más delitos son detectados, procesados y sancionados por el sistema de justicia criminal. En la medida en que algunos delincuentes suelen involucrarse en múltiples delitos que realmente no llegan a conocerse, su nivel de continuidad delictiva podría ser subestimado, al valorar que cometen menos delitos de los que realmente realizan. También es posible lo contrario, que los datos oficiales de la criminalidad sobrevaloren la continuidad delictiva, debido a los procesos de etiquetamiento de los delincuentes. Por ejemplo, si la policía tiene fichado a un individuo como delincuente crónico (debido a que cuenta con antecedentes delictivos desde la adolescencia), será más probable que, en el marco de la investigación criminal de delitos nuevos, tienda a sospechar de él más que de otras personas, lo que podría hacer que inconscientemente se construya y formalice la investigación criminal de forma que resulte más fácil detenerle (con lo cual se estaría inflando artificialmente la continuidad delictiva, medida en términos de detenciones policiales).

\section{Inicio adulto en el delito}

Como quiera que los expertos habían considerado en general que el comienzo adulto en la actividad delictiva era algo infrecuente (LeBlanc, 1998; Moffitt et al., 2001), hasta ahora han sido muy pocas las investigaciones que han analizado empíricamente el inicio adulto en la actividad criminal. Aun así, esta carencia investigadora no deja de resultar sorprendente, habida cuenta que también hubo algunos estudios sobre carreras delictivas que, como el de Blumstein et al. (1986), habían llamado la atención sobre el hecho de que "el 40-50 por ciento de los delincuentes adultos no presentaban antecedentes policiales juveniles" (p. 88). De ello fácilmente podría deducirse la existencia de una cantidad considerable de comienzos delictivos tardíos o adultos, a pesar de que no 
parece haber muchos predictores específicos que anticipan tal inicio adulto en la delincuencia.

Como resultado de todo ello, es muy escaso el conocimiento empírico disponible sobre el inicio delictivo en la edad adulta, además de que los pocos datos existentes presentan graves limitaciones. La primera es que muy pocos estudios sobre inicio delictivo adulto han incluido mujeres, con lo cual se conoce todavía menos en relación con ellas. La segunda es que la mayoría de los estudios no incluyen información de los sujetos sobre sus etapas adultas tempranas, próximas a la edad juvenil, de modo que pueda deslindarse con precisión si el inicio delictivo se produjo en uno u otro periodo. En tercer lugar, pocas investigaciones han podido comparar datos oficiales y de autoinforme correspondientes a la edad adulta, siendo mayoritarios los estudios que solo incluyen información delictiva oficial. Por último, para delitos no comunes, como evasión de impuestos, maltrato de pareja, y delitos de cuello blanco o relativos a los negocios, los indicadores de inicio criminal adulto pueden estar hasta cierto punto sesgados, dependiendo de las oportunidades delictivas que puedan ser más frecuentes en la vida adulta, para unos u otros individuos.

\section{Tendencias en términos de especialización, diversificación y escalada}

\section{delictiva}

La idea de que existen "delincuentes especializados", particularmente en relación con los delitos económicos y con los delitos sexuales, ha sido objeto constante de debate criminológico. Dos revisiones de amplio espectro de la bibliografía disponible a este respecto, convergen en tres conclusiones generales (Blumstein et al., 1986; Piquero, Paternoster, Brame, et al., 1999). La primera es que la mayoría de los delincuentes frecuentemente participan, a lo largo de su carrera criminal, en una amplia variedad de delitos, siendo pocos los sujetos que se concentran en una única tipología delictiva. En segundo lugar, aquellos delincuentes que muestran cierta especialización parecen orientar sus infracciones, no a un tipo concreto y único de delito, sino en torno a una categoría más amplia de delitos relacionados, por ejemplo, de infracciones contra la propiedad, pudiendo cometer tanto hurtos, como robos de vehículos, robos en casas, etc. En tercer lugar, existe alguna evidencia científica de que habría con la edad una ligera 
tendencia a la especialización, aunque, con los datos hasta ahora existentes, no puede formularse una conclusión definitiva a este respecto.

Para explorar estas cuestiones, algunos estudios han examinado la evolución de los patrones delictivos entre los periodos juvenil y adulto. Por ejemplo, Piquero et al. (1999), a partir de datos de la cohorte de sujetos nacidos en 1958 en Filadelfia, abarcando el período de edades comprendido entre 8 y 26 años, hallaron asociación entre la menor edad de inicio delictivo (según datos oficiales) y una mayor versatilidad o variabilidad de los delitos cometidos. Es decir, a medida que el inicio delictivo es más temprano, mayor sería la versatilidad delictiva y menor la especialización. Sin embargo, esta asociación estadística precocidad-versatilidad decayó tras controlar la variable edad, lo que sugiere que, con el tiempo, los delincuentes tenderían a hacerse un poco más especializados en sus delitos, independientemente de la edad de inicio delictivo.

Por lo que se refiere a los delitos violentos, en un análisis a largo plazo sobre especialización delictiva, a partir de las condenas que habían experimentado los varones del Estudio Cambridge hasta la edad de 40 años, Piquero et al. (2007) encontraron escasa evidencia de especialización en delitos violentos. Concluyeron que el predictor más potente de que un sujeto experimentara a lo largo de su carrera criminal alguna condena por un delito violento, era el hecho de contar con un mayor número de condenas en general (por diferentes tipos de delitos, no necesariamente violentos).

En otra investigación paralela, Loeber y col. (2008) examinaron la posible especialización de los sujetos en delitos violentos graves, a partir de datos de las dos cohortes de edades del estudio Pittsburgh a que ya se ha aludido con antelación (sujetos más jóvenes y más mayores). Encontraron que, en general, mientras que la mayoría de los delincuentes eran versátiles, y cometían tanto hurtos y robos como delitos violentos, una proporción relevante de ellos solo cometía delitos contra la propiedad o solo delitos violentos. En segundo lugar, también hallaron resultados ambivalentes sobre los cambios que se producían en la especialización con la edad. En el grupo de los sujetos más jóvenes, era más alta la especialización delictiva, en delitos de robo o en delitos violentos, en los intervalos de edades 10-12 años y 17-19 años, pero más baja entre las edades de 13 a 16 años. Sin embargo, en la cohorte de individuos de mayor edad, la especialización en delitos violentos aumentaba con la edad, desde una prevalencia de especialización del 53\% en la adolescencia temprana (entre las edades 13-16 años) a 
una tasa de especialización del 83\% en la primera edad adulta (edades 20-25 años); mientras que apareció escasa especialización en delitos contra la propiedad en la adolescencia tardía (17-19 años), que, sin embargo, aumentó a partir de la edad adulta temprana. Por último, los jóvenes que siguieron una trayectoria delictiva específica en determinada forma de delincuencia grave, también propendieron a seguir una trayectoria similar en otras formas de delincuencia grave. Es decir, quienes fueron delincuentes graves en delitos contra la propiedad también fueron, en la mayoría de los casos, delincuentes violentos graves.

Aparte de la cuestión de la especialización, a que se acaba de aludir, también son importantes los procesos de aceleración y desaceleración delictivas. La aceleración, o escalada criminal, se refiere a un aumento con el tiempo en la frecuencia o gravedad de los delitos, mientras que la desaceleración sería la evolución desde una actividad delictiva más frecuente o grave, a otra menos intensa. A partir de datos de auto-informe del Pittsburgh Youth Study, Loeber et al. (2008) encontraron que, en general, los delitos contra la propiedad suelen preceder temporalmente a los delitos violentos, lo que se hizo todavía más notorio en la cohorte de sujetos más jóvenes. Además, hallaron que la probabilidad de progresión o escalada a un estadio de mayor gravedad delictiva disminuía al incrementarse la gravedad de las conductas ilícitas, por lo que era infrecuente la ascensión hasta las formas más graves de violencia. Por último, entre la cohorte juvenil de mayor edad, la escalada hacia una delincuencia de mayor gravedad se relacionó, no con factores de riesgo específicos y cualitativamente diferentes de los habituales, sino con el hecho de que incidieran sobre el individuo un mayor número de los mismos factores que normalmente se asocian a una delincuencia leve o moderada.

Resumen. Los análisis sobre especialización delictiva permiten concluir que la mayoría de los delincuentes no se especializan de manera estricta, limitándose a la comisión de delitos muy específicos. Lo más habitual es que muchos delincuentes cometan diversas categorías de infracciones y delitos. Esta conclusión tiene un cariz bastante general, ya que resulta válida con respecto a diferentes muestras de sujetos, periodos temporales evaluados, medidas de delincuencia, y tipologías delictivas distintas (incluidos muchos delincuentes sexuales, a quienes suele presuponerse especialización criminal, no siendo así en muchos casos; Zimring et al., 2008, 2009). Sin embargo, debido a que son escasos los estudios sobre especialización delictiva que 
han analizado conjuntamente los periodos de las edades juveniles y de la adultez temprana, así como otras etapas posteriores de la vida, todavía es prematuro extraer conclusiones firmes y definitivas con respecto a la naturaleza de la especialización delictiva en relación con la edad y a lo largo del tiempo.

\section{Estabilidad y cambio}

Un hecho criminológico relevante, bien documentado, es la fuerte correlación que existe entre la actividad criminal anterior y posterior de un sujeto. Se han propuesto dos explicaciones principales para intentar dar cuenta de dicha asociación (Nagin y Paternoster, 1991, 2000). La primera sugiere que la correlación que frecuentemente se observa entre la actividad delictiva previa y posterior de los individuos sería debida, esencialmente, a las diferencias inter-individuales, que suelen tener una naturaleza relativamente estable. En función de ello, algunos sujetos presentarían cierta propensión estable para la comisión de delitos, mientras que otros no mostrarían tal propensión, lo que explicaría la firme correlación que se observa entre el comportamiento pasado y el posterior (criminal o no).

La segunda explicación aludiría, por el contrario, al estado o situación de dependencia contextual de los individuos, sugiriendo más bien que la conducta delictiva ejercería un efecto catalizador sobre los vínculos y apegos sociales de los sujetos, y viceversa, tales apegos condicionarían, a su vez, la estabilidad a largo plazo del comportamiento criminal. En este contexto, la experiencia habida con la actividad delictiva influiría directamente sobre el individuo y generaría más delincuencia posterior, esencialmente como resultado de un contagio delictivo, recíproco y duradero, entre personas que participan en el delito. Una tercera explicación, de cariz mixto o integrador, sugeriría que ambos procesos, diferencias inter-individuales e influencias contextuales, serían responsables, en diversos grados a lo largo de la vida, de la correlación que se observa entre conducta delictiva anterior y posterior.

Algunos estudios han evidenciado que los patrones de actividad criminal suelen caracterizarse tanto por cierta la estabilidad como por un relativo cambio de comportamiento, en el tránsito que va desde la delincuencia juvenil al comportamiento criminal en la adultez temprana. Un análisis destacable a este respecto correspondió, en 
Suecia, a Stattin y Magnusson (1991), quienes estudiaron, a partir de datos longitudinales relativos a 709 sujetos varones, la relación entre estabilidad y cambio de conducta, entre la infancia (hasta los 14 años), la adolescencia (15-20 años), y la adultez temprana (edades 21-30 años). En principio, hallaron poca estabilidad de la actividad delictiva oficialmente registrada. Al mismo tiempo, no observaron en general especialización delictiva a través de los diversos períodos temporales evaluados (infancia, adolescencia y adultez temprana), incluso en el comportamiento de aquellas personas que delinquieron en los diversos periodos. Un pequeño número de sujetos, que delinquieron en los tres intervalos temporales analizados, fueron los autores de la mayoría de los delitos que se contabilizaron para el conjunto de la muestra, mostrando dichos sujetos escasa especialización delictiva. En otro estudio de este tenor, en Estados Unidos, Nagin y Paternoster (1991) evaluaron una muestra de estudiantes de la escuela secundaria South Carolina, constatando sin embargo, a partir de datos de auto-informe, una correlación significativa entre la actividad criminal precedente y subsiguiente.

Sampson y Laub (1993; Laub, Nagin y Sampson, 1998; Laub y Sampson, 2003; Sampson, Laub y Wimer, 2006) examinaron la asociación existente entre detenciones anteriores y posteriores, a través de períodos temporales distintos, especialmente entre la segunda y tercera década de la vida. En relación con las explicaciones anteriormente propuestas, hallaron evidencia científica consistente a favor de una perspectiva mixta, integradora de las tesis de la heterogeneidad poblacional y de la dependencia contextual de los sujetos. Al respecto de esto último, constaron que eventos vitales tales como contraer matrimonio o establecer una relación de pareja, y particularmente el propio apego y la inversión personal vinculados a dicha relación afectiva, se asociaban frecuentemente a la interrupción de la actividad delictiva.

Otros estudios, tanto a partir de datos de auto-informe como de cifras delictivas oficiales, también provén apoyo empírico para un modelo explicativo mixto, que combine la consideración de la heterogeneidad y diferencias individuales que existen en la población con, a la vez, la atención a la dependencia e influencia contextual bajo la que se hallan los individuos, constatándose reiteradamente la influencia positiva que podría tener una relación de pareja satisfactoria. Por ejemplo, Horney, Osgood y Marshall (1995), a partir de datos delictivos de autoinforme recogidos en el estado norteamericano de Nebraska, Piquero, Brame, Mazerolle y Haapenan (2002), utilizando 
datos longitudinales de liberados condicionales en California (de edades entre 20 y 30 años), y Theobald y Farrington (2009), evaluando hasta la edad de 48 años a los sujetos (todos varones) del Estudio Cambridge, en todos los casos han documentado el efecto inhibidor del delito que tendría el matrimonio, aunque tal efecto positivo pueda estar modulado por la heterogeneidad que exista entre los individuos. Además, Paternoster y Brame (1997), utilizando datos de autoinforme del National Youth Survey (NYS), de Estados Unidos, encontraron que tanto la conducta antisocial precedente de los sujetos (que puede ser indicativa de cierta disposición infractora) como su contacto posterior con compañeros delincuentes, se asociaban significativamente a la delincuencia posterior, incluso después de haber controlado la posible influencia de la heterogeneidad interindividual no observada. Cernkovich y Giordano (2001) investigaron, a partir de datos sobre sujetos infractores y otros individuos institucionalizados en hogares de Ohio, los patrones de estabilidad y cambio de la actividad delictiva, entre la adolescencia y la edad adulta temprana. Su análisis indicó que, en ambas muestras, existía una fuerte asociación entre la actividad delictiva previa y posterior. Sin embargo, los niveles de vinculación social de los individuos se asociaron con la criminalidad adulta solo en la muestra de sujetos institucionalizados que no habían delinquido previamente, ya que entre los delincuentes institucionalizados existían muy escasas diferencias en cuento a sus patrones de vinculación social (que en muchos casos eran de cariz antisocial).

Resumen. El tema de la estabilidad o cambio entre la actividad delictiva previa y posterior resulta nuclear para múltiples e importantes debates teóricos en Criminología. Muchos estudios, a partir de diferentes tipos de muestras, mediciones de la actividad criminal, y períodos de evaluación, apoyan una explicación criminológica basada en la heterogeneidad o diferencias individuales en la población, como resultado de las cuales algunos sujetos (y no otros) mostrarían una propensión delictiva relativamente estable, lo cual conectaría su actividad delictiva pasada con la posterior. En paralelo, muchas investigaciones también evidencian los efectos criminogénicos que podría tener la dependencia contextual de los sujetos, lo que vincularía la actividad criminal posterior a las influencias sociales recibidas por el sujetos. En conjunto, estos resultados ampararían una explicación mixta, que tomara en consideración tanto las características particulares de los individuos, como el contagio delictivo que los sujetos experimentan 
como resultado de su vinculación con otros sujetos antisociales, y su relativa dependencia de ellos.

\section{Co-delincuencia}

El conocimiento científico sobre los patrones de co-delincuencia, o actividad criminal en grupo, es también una realidad delictiva poco conocida, en buena medida debido a la escasez de información individual de cariz longitudinal, la cual resulta imprescindible para poder estudiar las trayectorias personales de delincuencia y co-delincuencia a lo largo del tiempo (Goldweber, Dmitrieva, Cauffman, et al., 2011; McCord y Conway, 2002; McGloin y Piquero, 2009; Sarnecki, 2001). Por otra parte, al igual que sucede con otros aspectos de las carreras delictivas, la mayoría de la información existente sobre co-delincuencia corresponde al periodo juvenil, y son muy pocos los estudios que han relacionado los patrones de delincuencia y co-delincuencia, entre la etapa juvenil y la edad adulta.

Ampliando los análisis previos sobre co-delincuencia que efectuaron Reiss y Farrington (1991), Piquero et al. (2007) analizaron, a partir del Estudio Cambridge, la naturaleza y el alcance de la cooperación entre los sujetos a la hora de cometer delitos. Hallaron que la curva de edad de la co-delincuencia alcanzaba su cota máxima al final de la adolescencia y después disminuía con la edad. La co-delincuencia era más frecuente en algunos delitos, como robos personales y robos de casas, que en otros. Además, se encontró relación directa entre el número total de co-delincuentes con que un sujeto cooperaba a lo largo de su carrera criminal y la duración de dicha carrera. Mientras que los individuos con carreras delictivas de duración más corta ( $<5$ años) tendían a asociarse con un menor número de compañeros delincuentes, los que presentaban carreras delictivas muy largas (de 20 años o más) tenían muchos compañeros delincuentes a lo largo de su carrera delictiva (con un promedio de más de diez co-delincuentes).

Piquero et al. también encontraron que los delincuentes que habían experimentado una primera condena a edad muy temprana, propendían a tener un mayor número de compañeros de delitos a lo largo de su carrera criminal, que aquellos otros individuos cuya primera condena había sido más tardía. Al examinar en esta muestra a 
los sujetos reincidentes (concretados en 24 varones que, a la edad de 24 años, ya habían cometido un mínimo de diez delitos), se constató que el 53\% de sus delitos los habían cometido en solitario, o, contrariamente, que el 47\% los habían cometido en compañía de otros sujetos. En general, fue rara y atípica la actividad criminal exclusivamente en solitario o únicamente en compañía de otros, a la vez que tampoco se constató una tendencia clara a que los delincuentes permanecieran en el mismo patrón delictivo, es decir, delincuencia en solitario o co-delincuencia, en las las diferentes edades.

En otra investigación a este respecto, van Mastrigt y Farrington (2009) utilizaron el universo completo de infracciones registradas oficialmente por una gran fuerza policial metropolitana destinada en el norte de Inglaterra entre 2002 y 2005 (computándose en total 105.348 delitos, y 61.646 delincuentes). Examinaron las interrelaciones entre co-delincuencia, edad, sexo y tipo de delito, obteniendo los siguientes resultados principales. En primer lugar, solo una minoría de la delincuencia oficial registrada involucraba a varios delincuentes. En segundo término, en coherencia con lo que sucede con carácter general en la relación edad-delito, la co-delincuencia también disminuyó con la edad. En tercer lugar, la co-infracción fue mayor en el caso de las mujeres que en el de los hombres. Por último, la cooperación delictiva varió según el tipo de infracción, y fue más común para el robo de casas y el robo violento que para otros delitos.

Resumen. Son escasos los estudios empíricos sobre co-delincuencia en general, y más aún acerca de la evolución de los patrones de co-delincuencia entre los períodos juvenil y adulto. Esta escasez de estudios de co-delincuencia parece ser resultado directo de una sustancial carencia de datos sobre las características de los delitos específicos. Por ejemplo, muy pocas fuentes de datos longitudinales en criminología contienen información detallada sobre cada infracción cometida por cada delincuente en particular. Por otra parte, es muy variable el grado en que tal información se encuentra disponible en los registros oficiales, dependiendo ello de los diversos departamentos de policía y los diferentes servicios penitenciarios. Una prioridad de la investigación futura debería ser recoger datos de autoinforme, a nivel individual, con respecto a la naturaleza y las características de cada caso criminal a lo largo del tiempo. Esto permitiría obtener un mayor conocimiento acerca de la co-delincuencia, en conexión con los cambios que 
se operan en las relaciones y los contextos de amistad entre las etapas de la adolescencia y la vida adulta (Laub y Sampson, 2003; Moffitt, 1993).

\section{Conclusiones y recomendaciones}

Este trabajo revisa algunos de los principales hallazgos de la investigación sobre carreras criminales, con especial énfasis en los cambios observados en las dimensiones de la carrera delictiva entre la adolescencia y la edad adulta. Estos resultados pueden ser relevantes para una mejor comprensión de la naturaleza de la actividad delictiva, para la revisión y reformulación de las teorías criminológicas del desarrollo y del ciclo vital, y para las políticas públicas que habría que adoptar en relación con los infractores adolescentes y juveniles, incluida una mejor selección de medidas judiciales y de prevención e intervención con ellos. De la investigación analizada también pueden derivarse algunas recomendaciones para la investigación futura en este campo, así como para los profesionales técnicos que trabajan en él, y para quienes elaboran las políticas en esta materia, tal y como se comenta a continuación.

\subsection{Prioridades de investigación}

En primer lugar, sería necesario profundizar en el estudio de las carreras criminales, recogiendo para ello datos más completos, que incluyeran un seguimiento prolongado de los sujetos, con las siguientes características: 1) que dicho seguimiento se extendiera hasta la edad adulta; 2) que incorporara tanto datos de auto-informe como de registros delictivos oficiales, con el fin de poder evaluar a quienes cometen delitos, tanto si han sido detenidos como si no (Blumstein, Cohen, Piquero y Visher, 2010; Brame, Fagan, Piquero, et al., 2004); 3) que incluyera mediciones adicionales acerca de los cambios que se producen en las circunstancias vitales de los individuos, como puedan ser relacionarse con ciertos amigos o trasladarse a vivir a un barrio diferente; y 4) que la información recogida fuera la suficiente y apropiada para el estudio de los eventuales cambios de conducta delictiva que puedan producirse a lo largo del desarrollo de los individuos. Estos datos serían indispensables para poder analizar los cambios en las tendencias de las carreras criminales que tienen lugar durante la transición entre la 
adolescencia y la edad adulta; es decir, tanto para el análisis de los patrones de estabilidad y cambio delictivos, como de las posibles interrupciones y reinicios (o sea, la intermitencia) que caracterizan a muchas carreras criminales (Laub y Sampson, 2003; Piquero, 2004).

En segundo término se necesitaría también más investigación sobre las tendencias y patrones en las carreras delictivas de diferentes grupos demográficos, como puedan ser mujeres y varones, o individuos de diferentes étnicas o grupos sociales (Farrington et al., 2007; Piquero y Brame, 2008).

En tercer lugar, también es esencial comprender mejor los procesos que subyacen a los patrones dinámicos y cambiantes de la carrera criminal (especialización, reducción de la frecuencia, desaceleración, etc.), con el fin de entender en mayor grado la estructura de las carreras delictivas, en términos de duración, intensidad y gravedad. Este conocimiento es particularmente relevante por lo que se refiere a la transición delictiva desde la adolescencia a la edad adulta, ya que dicha transición suele coincidir con el pico superior en la curva de edad del delito, y podría ofrecer algunas sugerencias valiosas para las políticas de predicción del riesgo y de incapacitación criminal (Blumstein y Piquero, 2007).

En cuarto lugar, también se debería avanzar en el conocimiento sobre el inicio tardío en el delito, durante la adultez temprana, para analizar los predictores individuales y sociales de comienzo delictivo demorado, y para identificar las dimensiones de la transición de la adolescencia a la edad adulta que son susceptibles de influir en tal inicio delictivo retardado, y, en términos favorables, de aquellos aspectos que podrían contribuir a su prevención.

En quinto lugar, como ha podido verse anteriormente, la mayoría de los datos de investigación en este campo se han obtenido o bien a partir de registros oficiales o bien de auto-informes, siendo muy escasos los estudios que han podido combinar ambas fuentes de información (Lidz et al., 2007). Sin embargo, sería muy conveniente que, en futuras investigaciones, se combinaran ambas metodologías, con la finalidad de conocer mejor, al respecto de la relación edad-delito, la probabilidad que tiene cada delito autoinformado de ser formalmente perseguido y procesado (Kirk, 2006), así como para estimar, en términos de política criminal general, la proporción de conductas antisociales que no son formalmente perseguidas y controladas (Babinski, Hartsough y 
Lambert, 2001; Blumstein et al., 2010). Por otra parte, también sería muy útil, para lograr una información más completa y significativa de la conducta delictiva de los jóvenes, poder disponer de otros informes y datos posibles, como los que puedan ser facilitados, por ejemplo, por los padres, maestros, o amigos.

Por último, también sería necesario mejorar el conocimiento actual acerca de los cambios que se producen a lo largo del tiempo en la co-delincuencia, o actividad delictiva en la que intervienen y cooperan varios individuos. Para ello, se requeriría más investigación a este respecto, particularmente entre los periodos de la adolescencia y la edad adulta, algo que puede ser extremadamente útil tanto para una mejor comprensión teórica de los cambios en la co-delincuencia que puedan producirse en el decurso de esta transición, como, en general, para la mejora de la política criminal en relación con la delincuencia a estas edades, a lo que hace referencia el siguiente epígrafe final.

\subsection{Recomendaciones de política criminal}

El gran potencial aplicado del estudio de las carreras delictivas es poder proporcionar información útil a los profesionales y responsables políticos, de cara a poder tomar mejores decisiones relativas a la predicción, el castigo y la prevención o intervención sobre la delincuencia.

La predicción se dirige esencialmente a valorar y anticipar qué delincuentes podrían tener un riesgo más elevado de continuar cometiendo delitos graves, y a sugerir cuáles podrían ser las medidas más convenientes de control y de gestión de dicho riesgo. Para ello puede resultar fundamental el análisis de los procesos de continuidad delictiva, ya que diversos técnicos y funcionarios públicos habrán de tomar decisiones importantes acerca del internamiento o encarcelamiento de dichos delincuentes -algunos de los cuales, sin embargo, probablemente desistirán pronto del delito, mientras que otros persistirán en él durante su edad adulta. Por ello es tan importante que se preste atención a la cuestión de la continuidad de la conducta delictiva desde la delincuencia juvenil a la delincuencia adulta (Robins, 1978), y, de modo más amplio, a la continuidad o discontinuidad delictiva a lo largo de los diferentes periodos vitales.

Blumstein y Nakamura (2009) han analizado el problema fundamental de cuánto tiempo tardaría una persona, con antecedentes penales o no, en llegar a convertirse o no 
en delincuente de alto riesgo, y en qué medida estos patrones de escalada criminal pueden variar en función de las edades de inicio delictivo y de las diversas tipologías delictivas. Para explorar estas cuestiones, evaluaron una muestra de individuos detenidos por primera vez como adultos en el estado de Nueva York, en 1980. Ello permitió efectuar un análisis retrospectivo de los casos a lo largo de 27 años, incluyendo a sujetos de 16, 18 y 20 años, que habían sido detenidos por robo personal, robo en vivienda o agresiones agravadas. Los autores encontraron que el riesgo de reincidencia de los sujetos disminuía con el trascurso del tiempo, de manera que a medida que los sujetos pasaban más tiempo sin tornar a delinquir, cada vez se hacía más improbable que delinquieran. Pasado cierto número de años, sin haber reincidido, podía existir una certeza razonable de que la probabilidad de repetición delictiva era verdaderamente muy baja, equiparable a la de grupos de comparación no delincuentes. El conocimiento sobre la continuidad delictiva entre la adolescencia y la edad adulta temprana puede proporcionar asimismo información crítica acerca de la capacidad del personal de justicia para tomar decisiones eficaces y eficientes a la hora de administrar los recursos públicos en esta materia.

Además, un mejor conocimiento sobre las duraciones promedio de las carreras delictivas también puede ofrecer información útil a quienes han de tomar decisiones relativas a las sentencias y su ejecución. Por ejemplo, si este conocimiento nos informara de que las carreras criminales son en promedio cortas, la implicación más inmediata sería que, en general, deberían aplicarse condenas también cortas; mientras que si dicho conocimiento indicara que las carreras delictivas son más bien largas, entonces probablemente se requerirían, en promedio, penas más prolongadas (Blumstein y Piquero, 2007). Los pocos estudios que existen sobre duración de las carreras delictivas han hallado que éstas tienden a ser más bien de corta duración (generalmente, menos de diez años), lo que pone en cuestión muchas de las largas condenas que son habituales en la justicia penal de muchos de los países del mundo, incluidos Estados Unidos, y también España.

Aparte de las decisiones relativas a la predicción criminal y al castigo de los delincuentes, otras opciones de política criminal tienen que ver con la prevención tanto del inicio delictivo como de la persistencia en la carrera delictiva. Dos meta-análisis recientes han ofrecido resultados sólidos sobre la eficacia de los programas de 
prevención temprana con niños, de cara a reducir el riesgo de delincuencia juvenil y adulta. En el primero de estos estudios, Piquero et al. (2009) efectuaron un meta-análisis de cincuenta y cinco programas de capacitación para padres (desarrollados en Estados Unidos y otros países), y mostraron que dichas intervenciones eran eficaces para reducir los problemas de conducta desde la primera infancia. En un segundo meta-análisis, en este caso de treinta y cuatro programas diseñados para mejorar el autocontrol, en niños y adolescentes de hasta la edad de 10 años, Piquero et al. (2010) encontraron que estos programas mejoraban, en efecto, el autocontrol de los jóvenes y, al mismo tiempo, reducían su probabilidad de conducta delictiva.

Por lo que se refiere concretamente a España, varias recomendaciones pueden resultar en especial relevantes. La primera es que, para un descripción más precisa y completa de las realidades de la delincuencia juvenil (descripción actualmente bastante deficiente e inconexa), habría que mejorar sustancialmente la confección e integración de las cifras e informaciones policiales (autonómicas y estatales) sobre los delitos cometidos por los jóvenes. Además, estas cifras policiales deberían ser conectadas e integradas con las de los juzgados de menores, y con las correspondientes a las instituciones de menores en las diversas comunidades autónomas. Actualmente toda esta información se halla dispersa y desvinculada para el conjunto de España, siendo difícil conocer con veracidad y precisión la realidad delictiva de los menores, su evolución a lo largo del tiempo, el número de sujetos que cometen algún delito (la prevalencia delictiva), la frecuencia delictiva de los mismos, la co-delincuencia que pueda existir, cuántos jóvenes que inicialmente cometen delitos abandonan pronto su actividad ilícita, cuántos continúan y por cuánto tiempo, etc. Es decir, conocer para el caso de España, todos aquellos aspectos relevantes que, en relación con las carreras delictivas, han sido objeto de atención científica en este informe.

Se sabe internacionalmente, y también parcialmente en España, a través de los estudios de autoinforme y de reincidencia que se han realizado hasta la fecha, que la mayoría de los sujetos que han cometido infracciones en su adolescencia y juventud, dejan pronto de hacerlo, y que solo una pequeña proporción de menores mantienen una actividad delictiva persistente a lo largo de los años. Aun así, en el caso de España, lo anterior se sabe de una manera general, para grupos y muestras globales de individuos, pero no se conoce con precisión por lo que se refiere, no a grupos, sino a los individuos 
concretos, algo que solo puede explorarse mediante estudios longitudinales, de los cuales actualmente carecemos. Esta carencia de información más específica y concreta sobre la continuidad o desistimiento delictivos es caldo de cultivo propicio para la exageración y el alarmismo acerca de la delincuencia juvenil, y para el consiguiente populismo punitivo a este respecto. Por ello, una mejor descripción y conocimiento de la delincuencia juvenil en España, particularmente a partir de nuevos análisis longitudinales, constituiría un reto criminológico y social muy importante para los próximos años.

En conclusión, sobre la base de los resultados de investigación aquí revisados, en primer lugar, puede valorarse que los responsables de las políticas criminales y los profesionales de la justicia ya cuentan en la actualidad con conocimientos y opciones diversas, que podrían serles útiles a la hora de decidir qué hacer con los delincuentes graves del presente (y del futuro), tanto en términos de decisiones y estrategias a corto como a largo plazo. Sin embargo, un mejor conocimiento de las carreras delictivas, según lo aquí propuesto, podría ofrecer una información todavía mejor acerca de la actividad criminal a lo largo del tiempo, susceptible de ayudar a tomar decisiones de política criminal mejor informadas, más competentes y eficientes, en un marco de recursos públicos siempre costosos y limitados. 


\section{Referencias}

Babinksi, L. M., Hartsough, C. S., y Lambert, N. M. (2001). A comparison of selfreport of criminal involvement and official arrest records. Aggressive Behavior, 27, 44-54.

Bergman, L. R., y Andershed, A. (2009). Predictors and outcomes of persistent or agelimited registered criminal behavior: a 30-year longitudinal study of a Swedish urban population. Aggressive Behavior, 35 (2), 164-178.

Blumstein, A., Cohen, J., Piquero, A. R., y Visher, C. A. (2010). Linking crime and arrest processes to measure variations in individual arrest risk per crime. Journal of Quantitative Criminology, 26, 533-548.

Blumstein, A., Cohen, J., Roth, J. A., y Visher, C. A. (1986). Criminal careers and 'career criminals'. Washington, DC, National Academy Press.

Blumstein, A., y Nakamura, K. (2009). Redemption in the presence of widespread criminal background checks. Criminology, 47, 327-360.

Blumstein, A., y Piquero, A. R. (2007). Criminal careers research and rational sentencing policy. Criminology and Public Policy, 6, 679-688.

Brame, R., Fagan, J., Piquero, A. R., Schubert, C., y Steinberg, L. (2004). Criminal careers of serious delinquents in two cities. Youth Violence and Juvenile Justice, $2,256-272$

Bravo, A., Sierra, M.J., y del Valle, J. (2007). Evaluación de resultados de a medidas de responsabilidad penal juvenil en Asturias. Asturias: Gobierno del Principado de Asturias.

Capdevila, M., Ferrer, M., y Luque, E. (2006). La reincidencia en el delicte en la justicia de menors. Barcelona: Centre d'Estudis Jurídics i Formació Especializada (Colección Justicia y Sociedad, nº 25).

Capdevila, M., Ferrer, M., y Luque, E. (2008). Evolució del perfil dels joves infractors ingressats en centres educatius i taxa de reincidència. JUSTIDATA. Estadística básica de la justicia a Catalunya, 48.

Cernkovich, S. A., y Giordano, P. C. (2001). Stability and change in antisocial behavior: The transition from adolescence to early adulthood. Criminology, 39, 371-410.

DeLisi, M., y Beaver, K. M. (Eds.) (2011). Criminological theory: A life-course approach. Sudbury, MA: Jones and Bartlett Publishers.

Ellis, L., Beaver, K., y Wright, J. (2009). Handboolk of Crime Correlates. San Diego, CA: Elsevier. 
Espada Sánchez, J. P., Méndez, F. X., e Hidalgo, M. D. (2000). Consumo de alcohol en escolares: descenso de la edad de inicio y cambios en los patrones de ingesta. Adicciones, 12 (1), 57-64.

Farrington, D. P. (2005). Integrated developmental and life-course theories of offending. New Brunswick, NJ: Transaction.

Farrington, D. P., Jolliffe, D., Hawkins, J. D., Catalano, R. F., Hill, K. G., y Kosterman, R. (2007). Why are boys more likely to be referred to juvenile court? Gender differences in official and self-reported delinquency. Victims and Offenders, 3, 123-145.

Farrington, D. P., Jolliffe, D., Loeber, R., Stouthamer-Loeber, M., y Kalb, L. (2001). The concentration of offenders in families, and family criminality in the prediction of boys' delinquency. Journal of Adolescence, 24, 579-596.

Farrington, D. P., y Loeber, R. (2013). Two approaches to developmental/life-course theorizing. En F. Cullen y P. Wilcox, The Oxford Handbook of Criminological Theory. Oxford: Oxford University Press.

Farrington, D. P., Loeber, R., y Ttofi, M. M. (2012). Risk and protective factors for offending. En Welsh, B., y Farrington, D. P., The Oxford Handbook of Crime Prevention. Oxford: Oxford University Press.

Farrington, D. P., Ttofi, M. M., y Coid, J. W. (2009). Development of adolescence-limited, late-onset, and persistent offenders from age 8 to age 48. Aggressive Behavior, 35, 150-163.

Fernández Molina, E., Bartolomé, R., Rechea, C., y Megías, A. (2009). Evolución y tendencias de la delincuencia juvenil en España. Revista Española de Investigación Criminológica, Artículo 8, $N^{o} 7,1-30$.

García, J., Ortega, E. y De la Fuente, L. (2010). Juvenile offenders recidivism in Spain. A quantitative revision. En M. Frias y V. Corral (Eds). Bio-psycho-social Perspectives on Interpersonal Violence. Hauppauge, NY (USA): Nova Science Publishers.

Garrido Martín, E., Heras, A., y Gómez, N. (2000). Delincuencia juvenil en la ciudad de Salamanca 1999-2000. Tres volúmenes.

Goldweber, A., Dmitrieva, J., Cauffman, E., Piquero, A. R., y Steinberg, L. (2011). The development of criminal style in adolescence and young adulthood: Separating the lemmings from the loners. Journal of Youth and Adolescence, 40, 332-346.

Gudjonsson, G. H., Einarsson, E., Bragason, O. O., y Sigurdsson, J. F. (2006). Personality predictors of self-reported offending in icelandic studens. Psychology, Crime \& Law, 12(4), 383-393. 
Horney, J., Osgood, D. W., y Marshall, I. H. (1995). Criminal careers in the short-term: Intra-individual variability in crime and its relation to local life circumstances. American Sociological Review, 60, 655-673.

Kirk, D.S. (2006). Examining the divergence across self-report and official data sources on inferences about the adolescent life-course of crime. Journal of Quantitative Criminology, 22, 107-129.

Laub, J. H., Nagin, D. S., y Sampson, R. J. (1998). Trajectories of change in criminal offending: Good marriages and the desistance process. American Sociological Review, 63, 225-238.

Laub, J. H., y Sampson, R. J. (2003). Shared beginnings, divergent lives. Cambridge, MA: Harvard University Press.

Le Blanc, M. (1998). Screening of serious and violent juvenile offenders: Identification, classification, and prediction. En R. Loeber y D. P. Farrington (Eds.), Serious and violent juvenile offenders: Risk factors and successful interventions (pp. 167-193). Thousand Oaks, CA: Sage.

Le Blanc, M., y Loeber, R. (1998). Developmental criminology updated. En M. Tonry (Ed.), Crime and justice (Vol. 23, pp. 115-197). Chicago IL: Chicago University Press.

Lidz, C.W., Banks, S., Simon, L., Schubert, C., y Mulvey, E. P. (2007). Violence and mental illness: A new analytic approach. Law and Human Behavior, 31, 23-31.

Loeber, R., Farrington, D. P., Stouthamer-Loeber, M., y White, H. R. (2008). Violence and serious theft: Development and prediction from childhood to adulthood. New York: Routledge.

Loeber, R., y Le Blanc, M. (1990). Toward a developmental criminology. En M. Tonry y N. Morris (Eds.), Crime and justice (Vol. 12, pp. 375-473). Chicago IL: University of Chicago Press.

McCord, J. (1978). A thirty-year follow-up of treatment effects. American Psychologist, 33, 284-289.

McCord, J., y Conway, K. P. (2002). Patterns of juvenile delinquency and co-offending. En R. Waring, y D. Weisburd (Eds.), Crime and social organization (pp. 15-30). New Brunswick, NJ: Transaction.

McGloin, J. M., y Piquero, A. R. (2009). 'I wasn’t alone': Collective behaviour and violent delinquency. Australian and New Zealand Journal of Criminology, 42, 336-353.

Moffitt, T. E. (1993). Adolescence-limited and life-course-persistent antisocial behavior: A developmental taxonomy. Psychological Review, 100, 674-701. 
Moffitt, T. E., Caspi, M., Rutter, P., y Silva, A. (2001). Sex differences in antisocial behaviour: Conduct disorder, delinquency, and violence in the Dunedin Longitudinal Study. Cambridge, UK: Cambridge University Press.

Nagin, D. S. (2005). Group-based modeling of development. Cambridge, MA: Harvard University Press.

Nagin, D. S., y Paternoster, R. (1991). On the relationship of past to future participation in delinquency. Criminology, 29, 163-189.

Nagin, D. S., y Paternoster, R. (2000). Population heterogeneity and state dependence: State of the evidence and directions for future research. Journal of Quantitative Criminology, 16, 117-144.

Paternoster, R., y Brame, R. (1997). Multiple routes to delinquency? A test of developmental and general theories of crime. Criminology, 35, 49-84.

Piquero, A.R. (2004). The intermittency of criminal careers. En S. Maruna y R. Immarigeon (Eds.), Offender re-entry and desistance (pp. 102-129). Albany: SUNY Press.

Piquero, A. R., y Brame, R. (2008). Assessing the race-ethnicity-crime relationship in a sample of serious adolescent delinquents. Crime y Delinquency, 54, 390-422.

Piquero, A. R., Brame, R., Mazerolle, P., y Haapenan, R. (2002). Crime in emerging adulthood. Criminology, 40, 137-169.

Piquero, A. R., Farrington, D. P., y Blumstein, A. (2003). The criminal career paradigm: Background and recent developments. En M. H. Tonry (Ed.), Crime and justice: A review of research (Vol. 30, pp. 359-506). Chicago, IL: University of Chicago Press.

Piquero, A. R., Farrington, D. P., y Blumstein, A. (2007). Key issues in criminal career research: New analyses of the Cambridge study in delinquent development. Cambridge, UK: Cambridge University Press.

Piquero, A.R., Farrington, D. P., Welsh, B. C., Tremblay, R., y Jennings, W. (2009). Effects of early family/parent training programs on antisocial behavior and delinquency. Journal of Experimental Criminology, 5, 83-120.

Piquero, A. R., Jennings, W., y Farrington, D. P. (2010). On the malleability of selfcontrol: Theoretical and policy implications regarding a general theory of crime. Justice Quarterly, 27, 803-834.

Piquero, A. R., Paternoster, R., Brame, R., Mazerolle, P., y Dean, C. W. (1999). Onset age and specialization in offending behavior. Journal of Research in Crime and Delinquency, 36, 275-299.

Quetelet, A. (1842). A treatise on man and the development of his faculties. Edinburgh: Chambers. 
Rechea, C. (2008). Conductas antisociales y delictivas de los jóvenes en España. Informe para el Consejo del Poder Judicial (http://www.uclm.es/Criminologia/pdf/16_2008. pdf).

Rechea, C., Barberet, R., Montañés, J., y Arroyo, L. (1995). La delincuencia juvenil en España: autoinforme de los jóvenes. Madrid: Universidad de Castilla-La Mancha/ Ministerio de Justicia e Interior.

Redondo, S. (2008). Individuos, sociedades y oportunidades en la explicación y prevención del delito: Modelo del Triple Riesgo Delictivo (TRD). Revista Española de Investigación Criminológica, Artículo 7, N. 6. (accesible en: www.criminologia.net).

Redondo, S., y Garrido, V. (2013). Principios de Criminología (4a). Valencia: Ed. Tirant lo Blanch.

Redondo, S., y Martínez-Catena, A. (2012). Psicología Criminal. Barcelona: UOC.

Redondo, S., Martínez-Catena, A., y Andrés, A. (2011). Factores de éxito asociados a los programas de intervención con menores infractores. Informes, Estudios e Investigación 2011. Ministerio de Sanidad, Política Social e Igualdad (http://www.observatoriodelainfancia.msssi.gob.es/productos/pdf/factoresDeExi to.pdf.

Reiss, A. J., y Farrington, D. P. (1991). Advancing knowledge about co-offending: Results from a prospective longitudinal survey of London males. Journal of Criminal Law and Criminology, 82, 360-395.

Remschmidt, H., y Walter, R. (2009). Kinderdelinquenz: Gesetzesverstösse Strafmündiger und ihre Folgen. Heidelberg: Springer.

Robins, L. N. (1978). Sturdy childhood predictors of adult antisocial behaviour: Replications from longitudinal studies. Psychological Medicine, 8, 611-622.

Rodríguez, F.J., Martínez, A., Paíno, S.G., Hernández, E., e Hinojal, R. (2002). Drogodependencia y familia: realidad en la conducta delictiva de una muestra penitenciaria. Revista Española de Sanidad Penitenciaria, 4 (3), 84-90.

Sampson, R. J., y Laub, J. H. (1993). Crime in the making: Pathways and turning points through life. Cambridge, MA: Harvard University Press.

Sampson, R. J., Laub, J. H., y Wimer, C. (2006). Does marriage reduce crime? A counterfactual approach to within-individual casual effects. Criminology, 44, 465-508.

San Juan, C., Ocáriz, E., y de la Cuesta, J.L. (2007). Evaluación de las medidas en medio abierto del plan de justicia juvenil de la comunidad autónoma del País Vasco. Boletín Criminológico, 96. 
Sarnecki, J. (2009). Delinquent Networks. Youth Co-Offending. En Schneider, H. J. (Ed.), Internationales Handbuch der Kriminologie Band 2. Berlin: De Gruyter Recht.

Shaw, C. (1931). The jack-roller. Chicago, IL: University of Chicago Press.

Stattin, H., y Magnusson, D. (1991). Stability and change in criminal behaviour up to age 30. British Journal of Criminology, 31, 327-346.

Stouthamer-Loeber, M., Loeber, R., Stallings, R., y Lacourse, E. (2008). Desistance From and Persistence in Offending. En R. Loeber, D. P. Farrington, M. Stouthamer-Loeber, y H. R. White (eds.), Violence and Serious Theft: Development and Prediction From Childhood to Adulthood (pp. 269-306). New York: Routledge.

Theobald, D., y Farrington, D. P. (2009). Effects of getting married on offending: Results from a prospective longitudinal survey of males. European Journal of Criminology, 6, 496-516.

Tracy, P. E., y Kempf-Leonard, K. (1996). Continuity and discontinuity in criminal careers. New York: Plenum.

van Mastrigt, S.B., y Farrington, D. P. (2009). Co-offending, age, gender, and crime type: Implications for criminal justice policy. British Journal of Criminology, $49,552-573$.

Wolfgang, M., Figlio, R. M., y Sellin, T. (1972). Delinquency in a birth cohort. Chicago, IL: University of Chicago Press.

Wolfgang, M. E., Thornberry, T. P., y Figlio, R. M. (1987). From boy to man, from delinquency to crime. Chicago, IL: University of Chicago Press.

Zimring, F., Jennings, W., y Piquero, A. R. (2008). Juvenile and adult sexual offending in Racine, Wisconsin: Does early sex offending predict later sex offending in youth and young adulthood? Criminology and Public Policy, 6, 507-534.

Zimring, F., Jennings, W. G., Piquero, A. R., y Hays, S. (2009). Investigating the continuity of sex offending: Evidence from the Second Philadelphia Birth Cohort. Justice Quarterly, 26, 58-76. 